\title{
Latex Stability in Semibatch Surfactant-Free Seeded Emulsion Polymerization of Butyl Acrylate
}

\author{
Chorng-Shyan Chern, Chi-Huei LIN, and Tseng-Jung Chen \\ Department of Chemical Engineering, National Taiwan Institute of Technology, \\ Taipei 106, Taiwan, Republic of China
}

(Received September 2, 1996)

\begin{abstract}
The seeded technique was used to study particle growth mechanisms involved in semibatch surfactant-free emulsion polymerization of butyl acrylate (BA) in ordr to avoid complicated effects by particle nucleation. The data show that limited flocculation, often observed in the polymerization system containing no seed particles, did not occur in this work. This is attributed to the extensive formation of coagulum during polymerization. Agitation speed is the most important variable in determining the amount of total scrap produced, followed by initiator concentration, monomer feed rate, and then buffer concentration. A carboxylic seed latex was prepared to further study particle growth mechanisms. The level of coagulum for these runs using a carboxylic seed latex is much lower than that for the runs using an ordinary poly(butyl acrylate) seed latex. Limited flocculation was not observed during the reaction. In this case, nucleation of a second crop of primary particles during monomer addition was confirmed.
\end{abstract}

KEY WORDS Latex Stability/Emulsion Polymerization/Surfactant-Free / Semibatch / Butyl Acrylate /

Semibatch emulsion polymerization ${ }^{1-5}$ is widely used for industrial production of latex products such as coatings, adhesives, thermoplastics, and synthetic rubbers. Emulsion polymer particles ( $\mathrm{ca} .50-1,000 \mathrm{~nm}$ in diameter) are generally dispersed and stabilized in water by anionic and/or noninonic surfactants, which provide electrostatic and/or steric stabilization actions against the attractive van der Waals force. Conventional surfactant (e.g., sodium dodecyl sulfate) molecules are relatively small and mobile. These surface active species tend to migrate toward the surface layer of a polymeric film. As a result, the surface active agent remaining on the coating surfac has a negative effect on the application properties (e.g., adhesion and water resistance of pressure-sensitive adhesives).

One approach to overcome such a surfactant migration is the surfactant-free technique, ${ }^{4,5}$ in which latex particles are stabilized only by the surface sulfate end-group and/or carboxylic group (derived from the persulfate initiator and/or carboxylic monomers, respectively). It was shown that the latex particles can achieve appreciable stability by limited flocculation in the course of semibatch surfactant-free emulsion polymerization of butyl acrylate (BA). ${ }^{4}$ Limited flocculation ${ }^{4,6,7}$ involves the growth of latex particles via mild aggregation among themselves during the reaction. The degree of limited flocculation is greatly retarded by incorporation of a small amount of carboxylic monomers such as acrylic acid (AA) into the emulsion polymer. ${ }^{5}$ Limited flocculation inevitably makes the task of gaining an insight into the particle nucleation and growth mechanisms extremely difficult. Thus, it is necessary to focus on the evolution of primary particles during the very early stage of polymerization to reveal the particle nucleation mechanism, which will be the subject of a forthcoming paper. The seeded technique (i.e., number of particles in the reaction system is known immediately before the start of monomer feed) was used in this work to investigate particle growth mechanisms.

In addition to limited flocculation, a significant amount of coagulum due to intensive coagulation induced by severe reaction environment (such as inadequate mixing, monomer feed rate, and ionic strength, etc.) was observed in our previous report. ${ }^{4}$ At manufacturing facilities, removal of coagulum from the latex product by filtration is necessary because the coagulum in the latex product generally shows negative effect on the application properties. Furthermore, the reactor needs to be shut down for cleaning when polymer on the wall and agitator accumulates to an unacceptable level. Both factors cause production problems and increase the cost. Thus, a knowledge of the effects of various reaction parameters on the formation of coagulum during polymerization is essential for successful production.

The objective of this work was to systematically study the effects of important reaction parameters on the latex stability during semibatch surfactant-free seeded emulsion polymerization of BA. The parameters selected for study include the concentration of initiator, concentration of buffer (e.g., $\mathrm{NaHCO}_{3}$ used in this work), monomer feed rate, and agitation speed, etc. Both the percentage of particle volume change $(\Delta V)$ during monomer addition (attributed to limited flocculation) and amount of total scrap collected at the end of polymerization (attributed to intensive coagulation) were used to quantify the latex stability according to references 2 and 3 . Note that the parameter $\Delta V$ can be calculated by the following equation:

$$
\Delta V=\left[\left(d_{\mathrm{f}} / d_{\mathrm{f}}^{\prime}\right)^{3}-1\right] \times 100 \%
$$

where $d_{\mathrm{f}}$ is the measured particle diameter of the latex product and $d_{\mathrm{f}}^{\prime}$ is the calculated particle diameter of the final latex when neither secondary nucleation (i.e., generation of a second crop of primary particles) nor limited flocculation occurs during monomer addition. For example, if $d_{\mathrm{s}}(\mathrm{nm})$ and $N_{\mathrm{p}}$ are the seed particle diameter and total number of seed particles initially charged into the reaction system, respectively, $W_{\mathrm{m}}(\mathrm{g})$ is the total weight of fed monomer, and $\rho\left(\mathrm{g} \mathrm{cm}^{-3}\right)$ is the density of polymer, $d_{\mathrm{f}}^{\prime}$ is thus calculated according to the 
following equation:

$$
d_{\mathrm{f}}^{\prime}=\left[d_{\mathrm{s}}^{3}+6 \times 10^{21} W_{\mathrm{m}} /\left(\pi \rho N_{\mathrm{p}}\right)\right]^{1 / 3}
$$

\section{EXPERIMENTAL}

\section{Materials}

The chemicals used were: butyl acrylate (BA) (Formosa Plastics Co.); acrylic acid (AA) (Formosa Plastics Co.); sodium persulfate (Riedel-de-Haen); sodium bicarbonate (Nacalai Tesque, Inc.); sodium hydroxide (Riedel-deHaen); nitrogen (Ching-Feng-Harng Co.); deionized water (Barnsted, Nanopure Ultrapure Water System, specific conductance $<0.057 \mu \mathrm{S} \mathrm{cm}^{-1}$ ). The primary monomer BA was distilled under reduced pressure before used. All other chemicals were used as received.

\section{Polymerization Process}

Semibatch emulsion polymerization was carried out in a 1-liter glass reactor equipped with a 4-bladed agitator, a thermometer, and a condenser. A typical recipe is shown in Table I. The initial reactor charge (including water, seed latex, and $\mathrm{NaHCO}_{3}$ ) was purged with nitrogen for $10 \mathrm{~min}$ to remove dissolved oxygen while heated to $80^{\circ} \mathrm{C}$, followed by addition of the initiator solution. The monomer was then fed into the reactor over a prescribed period of time by an FMI pump. The reaction temperature was kept at $80^{\circ} \mathrm{C}$ throughout the reaction. Seed particles were kept at $10.35 \%$ based on total polymer. The total solid content of the latex product was about $45 \%$ for complete monomer conversion.

Two seed latices prepared by a similar semibatch process in a 2-liter reactor were selected for this study. The recipe for the first seed latex is: $1348.00 \mathrm{~g} \mathrm{H}_{2} \mathrm{O}$, $0.88 \mathrm{~g} \mathrm{NaHCO}_{3}, 4.20 \mathrm{~g} \mathrm{Na}_{2} \mathrm{~S}_{2} \mathrm{O}_{8}$, and $161.60 \mathrm{~g} \mathrm{BA}$. The target total solid content of the seed latex is $11 \%$. The monomer feed rate and agitation speed were set at $0.93 \mathrm{~g} \mathrm{~min}^{-1}$ and $600 \mathrm{rpm}$, respectively, throughout the reaction. After monomer feeding was complete, the latex was held at $80^{\circ} \mathrm{C}$ for five more hours to deplete the initiator species. The resultant product had an average particle size of $217 \mathrm{~nm}$ (an average of eight batches). Similarly, the second seed latex consisted of $1348.00 \mathrm{~g}$ $\mathrm{H}_{2} \mathrm{O}, 0.88 \mathrm{~g} \mathrm{NaHCO}_{3}, 4.20 \mathrm{~g} \mathrm{Na}_{2} \mathrm{~S}_{2} \mathrm{O}_{8}, 157.56 \mathrm{~g} \mathrm{BA}$, and $4.04 \mathrm{~g} \mathrm{AA}(2.5 \mathrm{wt} \%$ based on total monomer). The target total solid content was $11 \%$. The average particle size of the carboxylic seed latex was $187 \mathrm{~nm}$ (an average of eight batches). The seed latices were dialyzed ( $\mathrm{MWCO}=$ $12000-14000 \mathrm{~g} \mathrm{~mol}^{-1}$ ) extensively against deionized water for five days before use to remove residual monomer, initiator, and other impurities.

Table I. Typical recipe for semibatch surfactant-free seeded emulsion polymerization of BA

\begin{tabular}{lcr}
\hline & Chemicals & Weight $/ \mathrm{g}$ \\
\hline Monomer feed & $\mathrm{BA}$ & 222.00 \\
Initial reactor charge & $\mathrm{H}_{2} \mathrm{O}$ & 75.00 \\
& Seed $(10.68 \%$ active $)$ & 240.00 \\
& $\mathrm{NaHCO}_{3}$ & 0.61 \\
Initiator solution & $\mathrm{H}_{2} \mathrm{O}$ & 15.00 \\
& $\mathrm{Na}_{2} \mathrm{~S}_{2} \mathrm{O}_{8}$ & 0.55 \\
Total weight $/ \mathrm{g}$ & & 553.16 \\
Total solid content $/ \%$ & & 45.00 \\
\hline
\end{tabular}

\section{Characterization}

The latex product was filtered through a 40-mesh $(0.42 \mathrm{~mm})$ screen and a 200 -mesh $(0.074 \mathrm{~mm})$ screen in series to collect large flocs. Scraps adhering to the agitator, thermometer, and reactor wall were also collected. Total solid conent was determined by the gravimetric method. Particle size data were obtained from the dynamic light scattering method (Otsuka, Photal LPA-3000/3100) due to the difficulties encountered in examining the very soft polybutyl acrylate particles $\left(T_{\mathrm{g}}=-54^{\circ} \mathrm{C}\right)$ by transmission electron microscopy.

\section{RESULTS AND DISCUSSION}

\section{Fractional Two-Level Factorial Design}

First, the concentration of buffer ([B], 0.05- $0.45 \%$ based on total water), concentration of initiator ([I], $0.11-0.25 \%$ based on total water), monomer feed rate $\left(F_{\mathrm{m}}, 0.9-1.9 \mathrm{~g} \mathrm{~min}^{-1}\right)$, and agitation speed $(\mathrm{S}, 400$ $900 \mathrm{rpm})$ were chosen as variables of a fractional twolevel factorial design $\left(2^{4-1}+1=9\right.$ points in a designed cube, 1 midpoint included) to quantitatively analyze their effects on total scrap and $\Delta V$. The numeric values in the above parenthesis represent the lowest level (-) and the highest level $(+)$ in the factorial design.

Each point (recipe) was carried out twice to test the batch-to-batch variations in this series of experiments. The experimental data are compiled in Table II. For reference, the overall average data of $d_{\mathrm{f}}, d_{\mathrm{w}} / d_{\mathrm{n}}$, total scrap, and $\Delta V$ are also included in this table. Total scrap represents the large flocs collected by a 40 -mesh screen and 200-mesh screen in series plus those adhering to the agitator, thermometer, and reactor wall. The overall average of the total scrap data is $5.62 \%$. Such a high level of coagulum can cause serious problems in plant production. The reproducibility for the data of $d_{\mathrm{f}}, d_{\mathrm{w}} / d_{\mathrm{n}}$, and total scrap is reasonably good. On the other hand, the $\Delta V$ data are rather scattered.

The positive sign of $\Delta V$ implies that limited flocculation occurred in the course of monomer addition. The greater the value of $\Delta V$ is, the stronger is the limited flocculation of the seed particles. On the other hand, the negative sign of $\Delta V$ implies the generation of a second crop of primary particles or coagulation of larger particles of a normally distributed population. The former is unlikely to happen because no surfactant is incorporated into the polymerization system and the particle nuclei generated in water are prone to be captured by seed particles. The latter seems reasonable because the shear-induced collision frequency is proportional to the cube of particle radius and this could shift the average particle size slightly toward the lower end. Nevertheless, the magnitude of $\Delta V$ is quite small throughout this series of experiments (the overall average of the $\Delta V$ data is only $6 \%$ ). This is very interesting since limited flocculation associated with the surfactant-free polymerization system containing no seed particles ${ }^{4}$ has not been observed in this seeded polymerization system. It is speculated that limited flocculation does take place during the early stage of monomer addition. However, the reaction environment is so hostile that the latex particles undergoing limited flocculation finally go out of control and, consequently, become large flocs toward the end of 
Table II. Experimental data obtained from fractional two-level factorial design ${ }^{\text {a }}$

\begin{tabular}{|c|c|c|c|c|c|c|}
\hline \multirow{2}{*}{ [B], } & \multirow{2}{*}{\multicolumn{2}{|c|}{$[\mathrm{I}], \quad F_{\mathrm{m}}, \quad S$}} & $d_{\mathrm{f}}$ & \multirow{2}{*}{$d_{\mathrm{w}} / d_{\mathrm{n}}^{\mathrm{b}}$} & \multirow{2}{*}{$\frac{\text { Total scrap }^{\mathrm{c}}}{\%}$} & \multirow{2}{*}{$\frac{\Delta V}{\%}$} \\
\hline & & & $\mathrm{mm}$ & & & \\
\hline 0.05 , & 0.11 & $0.9,400$ & $451 \pm 30$ & $1.08 \pm 0.00$ & $4.70 \pm 0.44$ & $-5 \pm 19$ \\
\hline 0.45 , & 0.11 & $0.9,900$ & $424 \pm 21$ & $1.12 \pm 0.01$ & $7.62 \pm 1.39$ & $-21 \pm 11$ \\
\hline 0.05 , & 0.25 & $0.9,900$ & $460 \pm 5$ & $1.08 \pm 0.04$ & $15.20 \pm 5.26$ & $-1 \pm 3$ \\
\hline 0.45 , & 0.25 & $0.9,400$ & $472 \pm 7$ & $1.06 \pm 0.00$ & $0.72 \pm 0.09$ & $8 \pm 5$ \\
\hline 0.05 , & 0.11 & $1.9,900$ & $491 \pm 13$ & $1.09 \pm 0.06$ & $3.65 \pm 0.83$ & $21 \pm 10$ \\
\hline 0.45 , & 0.11 , & $1.9,400$ & $452 \pm 5$ & $1.11 \pm 0.01$ & $2.42 \pm 0.12$ & $-6 \pm 3$ \\
\hline 0.05 , & 0.25 & $1.9,400$ & $467 \pm 23$ & $1.19 \pm 0.11$ & $1.78 \pm 0.00$ & $4 \pm 15$ \\
\hline 0.45 , & 0.25 & $1.9,900$ & $378 \pm 19$ & $1.14 \pm 0.04$ & $11.40 \pm 1.74$ & $-45 \pm 8$ \\
\hline 0.25 , & 0.18 & $1.4,650$ & $424 \pm 20$ & $1.05 \pm 0.00$ & $3.09 \pm 0.14$ & $-22 \pm 11$ \\
\hline & erall a & iverage & 447 & 1.10 & 5.62 & 6 \\
\hline
\end{tabular}

${ }^{\text {a }}$ Data are the average of two identical experiments. ${ }^{\mathrm{b}} d_{\mathrm{w}} / d_{\mathrm{n}}$ polydispersity index of particle size distribution. " Total scrap includes the 40-mesh scrap, 200-mesh filterable solids, and that adhering to the agitator, thermometer, and reactor wall.

Table III. Standardization effects of variables on total scrap and $\Delta V$

\begin{tabular}{lccccc}
\hline Variable & {$[\mathrm{B}]$} & {$[\mathrm{I}]$} & $F_{\mathrm{m}}$ & $S$ & $\begin{array}{l}\text { Overall } \\
\text { average }\end{array}$ \\
\hline $\begin{array}{l}\text { Total scrap } / \% \\
\Delta V / \%\end{array}$ & -0.79 & 2.68 & -2.25 & 7.06 & 5.62 \\
& -21 & -6 & -1 & -12 & 6 \\
\hline
\end{tabular}

polymerization. The relatively scattered $\Delta V$ data shown in Table II imply that limited flocculation is quite sensitive to the reaction environment and only a minor change in the hostile environment may cause the flocculated particles to be converted into large coagulum. In addition, the particle size distribution data $\left(d_{\mathrm{w}} / d_{\mathrm{n}}\right)$ indicate that the latex products are relatively narrow.

Table III lists the standardized effects of the variables on total scrap and $\Delta V$ when the variables are changed from the lowest level to the highest level. The data show that the agitation speed $(S,+7.06 \%)$ is the most important parameter in determining the level of coagulum produced, followed by the concentration of initiator ([I] $]+2.68 \%)$ and then the monomer feed rate $\left(F_{\mathrm{m}},-2.25 \%\right)$. The concentration of buffer shows the smallest effect ([B], $-0.79 \%$ ). The numeric value in the above parenthesis represents the standardized effects of variables on total scrap when changed from the lowest level to the highest level. As discussed above, all the reaction variables show an insignificant influence on $\Delta V$.

Based on this factorial design, the following empirical equation was derived to predict the amount of total scrap produced during monomer addition.

$$
\begin{aligned}
& \text { Total } \operatorname{scrap}(\%)=21.4171-27.8719[\mathrm{~B}]-49.7982[\mathrm{I}] \\
& \quad+2.2139 F_{\mathrm{m}}-0.05045 S-8.4171[\mathrm{~B}]^{2} \\
& +232.0759[\mathrm{I}]^{2}-3.8210 F_{\mathrm{m}}^{2}+4.7984 \times 10^{-5} S^{2} \\
& \quad-58.5201[\mathrm{~B}][\mathrm{I}]+24.9437[\mathrm{~B}] F_{\mathrm{m}} \\
& +8.7860 \times 10^{-3}[\mathrm{~B}] S
\end{aligned}
$$

Figure 1 shows contour plots of total scrap at [B] $=0.25 \%$ and $F_{\mathrm{m}}=1.4 \mathrm{~g} / \mathrm{min}$, constructed from eq 3 . The contour plots at various levels of $F_{\mathrm{m}}$ also show a

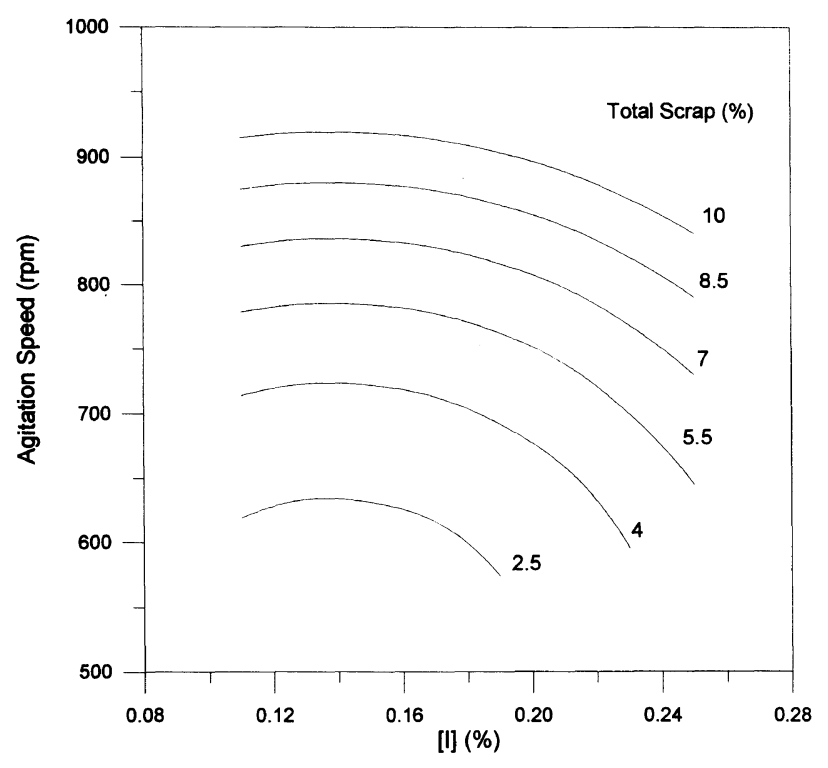

Figure 1. Contour plot of total scrap. [B] $=0.25 \%$ and $F_{\mathrm{m}}=1.4 \mathrm{~g}$ $\min ^{-1}$.

Table IV. Experiments to verify predictive equation of total scrap

\begin{tabular}{cccc}
\hline & $H$ & $M$ & $L$ \\
\hline Recipes: & & & \\
{$[\mathrm{B}] / \%$} & 0.25 & 0.25 & 0.25 \\
{$[\mathrm{I}] / \%$} & 0.230 & 0.186 & 0.135 \\
$F_{\mathrm{m} / \mathrm{g} \mathrm{min}} \mathrm{m}^{-1}$ & 1.4 & 1.4 & 1.4 \\
$S / \mathrm{rpm}$ & 869 & 767 & 635 \\
Results: & & & \\
Predicted total scrap/\% & 10.01 & 5.50 & 2.50 \\
Experimental data/\% & 10.80 & 5.22 & 3.52 \\
Error/\% & 8 & 5 & 41 \\
\hline
\end{tabular}

similar trend. At constant [I], the total scrap increases rapidly with agitation speed due to the increased frequency of collision among the particles. In considering the curve with total scrap equal to $5.5 \%$, for example, the agitation speed required to maintain the same level of total scrap first remains relatively constant and then decreases when initiator concentration increases. At constant agitation speed (e.g., $750 \mathrm{rpm})$, the total scrap first remains relatively constant $(\mathrm{ca} .5 .5 \%)$ when the initiator concentration increases from $0.11 \%$ to $0.17 \%$. Subsequently, the total scrap starts to increase gradually from about $5.5 \%$ to $8.5 \%$ when the initiator concentration is increased from $0.17 \%$ to $0.25 \%$, as shown in Figure 1. However, the effect of the initiator concentration on the coagulum formation is not as strong as that of the agitation speed.

Three formulae $(H, M$, and $L)$ were then selected to verify the predictive equation developed for total scrap (see eq 3). The recipes and experimental data are listed in Table IV. The total scrap data agree reasonably well with the predictions except for the experiment $L$. The larger deviation observed for the experiment $L$ is probably due to the condition that the colloidal system is closer to the stability-instability borderline. The total amount of scrap collected at the end of the reaction becomes more sensitive to small error in measuring reagents (e.g., initiator, buffer, etc.) and operational conditions (e.g., agitation speed, monomer feed rate, etc.). 


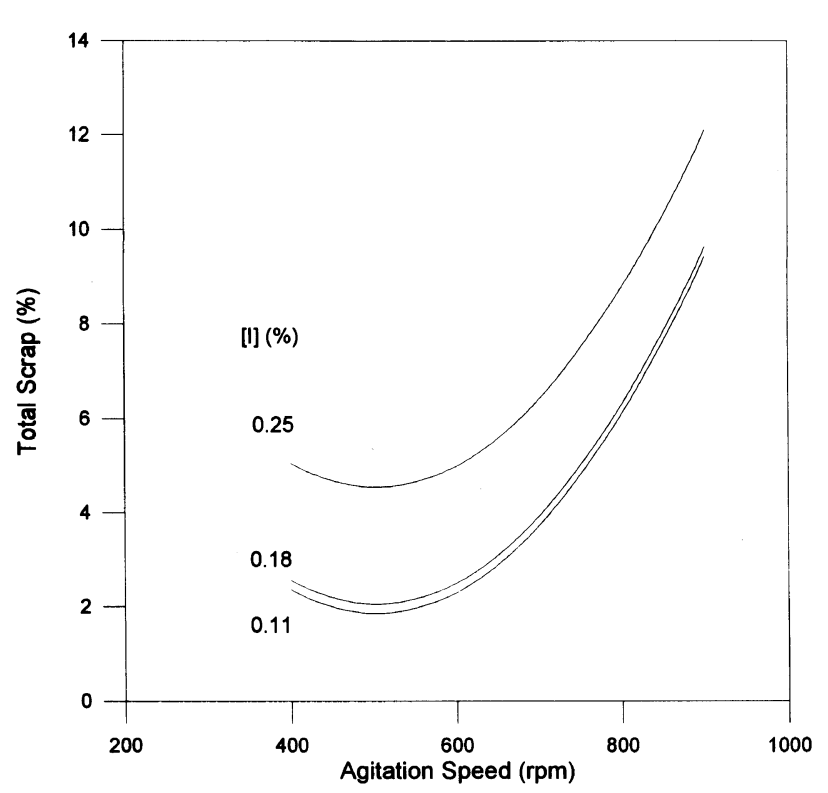

Figure 2. Effect of agitation speed on total scrap at various levels of initiator concentration. $[\mathrm{B}]=0.25 \%$ and $F_{\mathrm{m}}=0.25 \%$ and $F_{\mathrm{m}}=1.4 \mathrm{~g}$ $\min ^{-1}$.

Based on these experiments, the validity of using eq 3 for qualitatively predicting the formation of large coagulum during polymerization was further confirmed. Some of the results of the predictive equation for total scrap will be shown in the following three subsections. These experimental results support the above conclusion that the experiment with higher levels of agitation speed and initiator loading produces more coagulum (see Figure 1).

\section{Effect of Agitation Speed}

When the parameters [B] and $F_{\mathrm{m}}$ are set at $0.25 \%$ and $1.4 \mathrm{~g} \mathrm{~min}^{-1}$, respectively, total scrap versus agitation speed curves at various levels of [I] is shown in Figure 2 (constructed from the predictive equation for total scrap). At constant [I], the total scrap first decreases to a minimum and, thereafter, starts to increase with agitation speed. Total scrap is minimal at an agitation speed of about $500 \mathrm{rpm}$. The increase in the total scrap with agitation speed $(500-900 \mathrm{rpm})$ can be attributed to increased shear force. The strong shear force generated by intensive mixing causes significant turbulence in a stirred-tank reactor. This increases both the force and frequency of collisions among the interactive particles. Such a shear-induced coagulation process results in increase in coagulum produced during polymerization. On the other hand, the decrease in the total scrap with agitation speed $(400-500 \mathrm{rpm})$ is probably caused by improved dispersion of monomer in water and mass transfer of monomer to the reaction loci (particles). The huge monomer droplets caused by insufficient mixing might capture oligomeric radicals generated in water. If this event happen, bulk polymerization occurs inside the monomer droplets. Thus, the polymerized droplets are transformed into large flocs.

At constant agitation speed, the effect of [I] on total scrap is insignificant when the initiator concentration increases from $0.11 \%$ to $0.18 \%$, as illustrated in Figure 2. Total scrap produced at $[\mathrm{I}]=0.25 \%$ jumps up to

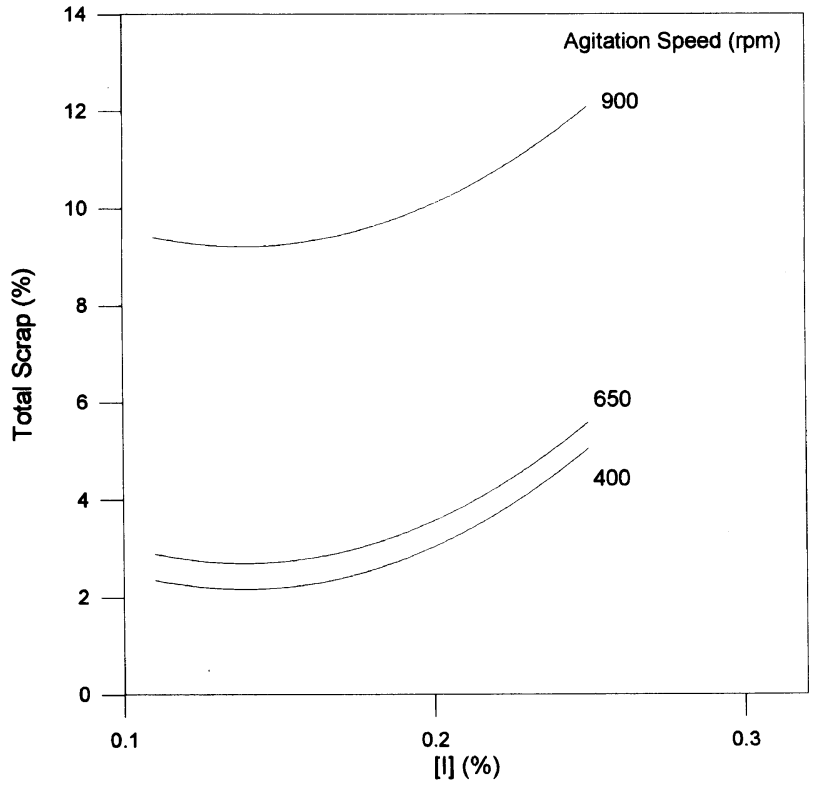

Figure 3. Effect of initiator concentration on total scrap at various levels of agitation speed. [B] $=0.25 \%$ and $F_{\mathrm{m}}=1.4 \mathrm{~g} \mathrm{~min}^{-1}$.

about $1.3-2.0$ times that produced at $[\mathrm{I}]=0.11-$ $0.18 \%$.

\section{Effects of Initiator Concentration}

Figure 3 shows the effects of [I] on total scrap at various levels of agitation speed according to eq 3 . In this figure, the parameters $F_{\mathrm{m}}$ and [B] are kept constant at $1.4 \mathrm{~g} \mathrm{~min}^{-1}$ and $0.25 \%$, respectively. At constant agitation speed, the total scrap first remains relatively constant up to $[I]=0.18 \%$ and, thereafter, starts to increase monotonously with [I]. This is due to the fact that the amount of sulfate end-group $\left(-\mathrm{SO}_{4}^{-}\right)$and concentration of sodium ion derived from the persulfate initiator increase with [I]. When the parameter [I] is below $0.18 \%$, the electrostatic stabilization effect provided by $-\mathrm{SO}_{4}^{-}$counteracts the ionic strength effect provided by the counterion $\mathrm{Na}^{+}$which tends to destabilize the latex particles. As a result, the amount of total scrap is relatively independent of [I] in this region. On the other hand, the ionic strength effect comes into play and starts to override the electrostatic stabilization effect when the initiator concentration is above $0.18 \%$. This action leads to decrease in the latex stability with increasing $[\mathrm{I}]$, thereby, increasing total scrap.

At constant [I], the effect of agitation speed on total scrap is again insignificant when the agitation speed increases from 400 to $650 \mathrm{rpm}$ (see Figure 3). On the other hand, the total scrap produced at an agitation speed of $900 \mathrm{rpm}$ jumps up to about 3-4 times that produced at an agitation speed of $400-650 \mathrm{rpm}$. In this case, the relative change in the total scrap with agitation speed is greater than that with [I]. This supports the conclusion that the agitation speed plays an important role in the formation of coagulum. The second most important parameter is the initiator concentration. However, these two parameters become significant only when their magnitudes are high enough (see Figures 2 and 3). 


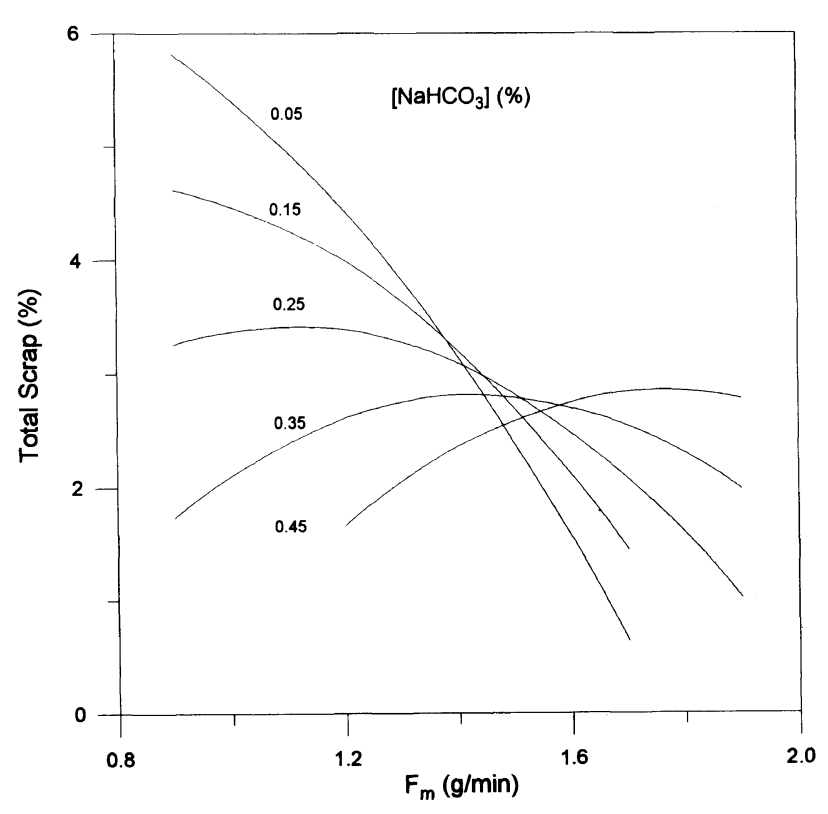

Figure 4. Effect of monomer feed rate on total scrap at various levels of buffer concentration. Agitation speed $=650 \mathrm{rpm}$ and $[\mathrm{I}]=0.18 \%$.

\section{Effects of Monomer Feed Rate and Buffer Concentration}

As discussed above, the parameter $F_{\mathrm{m}}$ also displays significant influence on the amount of coagulum produced during monomer addition (standarized effect is $-2.25 \%$ as listed in Table III). Figure 4 shows the total scrap versus $F_{\mathrm{m}}$ profiles at various levels of [B] based on eq 3 . In this figure, the agitation speed and [I] are set at $650 \mathrm{rpm}$ and $0.18 \%$, respectively. A crossover at $F_{\mathrm{m}}=1.5 \mathrm{~g} \mathrm{~min}^{-1}$ is observed in Figure 4. At lower levels of $F_{\mathrm{m}}\left(e . g ., F_{\mathrm{m}}<1.5 \mathrm{~g} \mathrm{~min}^{-1}\right)$, the total scrap decreases rapidly with increasing $[\mathrm{B}]$. The reverse trend is observed when the parameter $F_{\mathrm{m}}$ is greater than $1.5 \mathrm{~g} \mathrm{~min}^{-1}$. Examining Figure 4 in a different way reveals that the total scrap decreases rapidly with increasing $F_{\mathrm{m}}$ when the buffer concentration is below $0.25 \%$. Total scrap first increases and then levels off when the buffer concentration is above $0.35 \%$. When [B] is located between (i.e., $[\mathrm{B}]=0.25-0.35 \%$ ), total scrap first increases to a maximum with $F_{\mathrm{m}}$ and, thereafter, decreases with increasing $F_{\mathrm{m}}$.

In addition to $\mathrm{pH}$ control, the reagent $\mathrm{NaHCO}_{3}$ shows twofold effect on the polymerization system. First, the concentration of electrolyte increases with [B]. According to the DLVO theory, ${ }^{8,9}$ enhanced ionic strength compresses the electric double layer of the latex particles to reduce repulsive force among interactive particles. This action causes a reduction in the latex stability and, therefore, increases the extent of coagulum formation. Secondly, the reagent $\mathrm{NaHCO}_{3}$ promotes inoization of the carboxyl group $(-\mathrm{COOH})$ on the particle surace, derived from hydrolysis of $-\mathrm{SO}_{4}^{-}$and subsequent oxidation of the generated hydroxyl group $(-\mathrm{OH}) .{ }^{10}$ This stabilization effect reduces total scrap produced during polymerization.

When [B] is lower than $0.25 \%$, the above mentioned effects associated with $\mathrm{NaHCO}_{3}$ are not important and latex stability is controlled by the parameter $F_{\mathrm{m}}$ instead. The faster the monomer feed rate, the shorter are the polymer particles subject to intensive mixing. Thus, total scrap should decrease with increasing $F_{\mathrm{m}}$ in the region of $[\mathrm{B}]<0.25 \%$. On the other hand, it is postulated that the number of ionized carboxyl groups increases with decreasing $F_{\mathrm{m}}$ when the buffer concentration is higher than $0.35 \%$. This might be because more sulfate endgroups on the particle surface are converted to carboxyl groups as the residence time of the particles in the reactor is increased. In this case, the stabilization effect provided by ionization of $-\mathrm{COOH}$ becomes more important. In the region of $[\mathrm{B}]>0.35 \%$, the amount of total scrap collected at the end of polymerization may thus increase with $F_{\mathrm{m}}$. For $[\mathrm{B}]=0.25-0.35 \%$, the formation of coagulum is determined by the competitive effects discussed above. Thus, in the region of slower monomer feed rates, increase in the total scrap with $F_{\mathrm{m}}$ occurs because electrostatic stabilization provided by ionization of $-\mathrm{COOH}$ overrides the effects of the time for the latex particles subject to intensive mixing and relatively high ionic strength. On the other hand, in the region of faster monomer feed rates, the decrease in the total scrap with $F_{\mathrm{m}}$ can be attributed to the fact that the stabilization provided by ionization of - $\mathrm{COOH}$ becomes insignificant compared to the length of time for latex particles subject to mechanical agitation and relatively high ionic strength.

The effect of [B] on the formation of coagulum is very important, especially when the monomer feed rate is relatively slow (see Figure 4). However, the calculated standardized effect of [B] on total scrap is only $-0.79 \%$ (see Table III). The reason for the contradiction in the significance of the parameter [B] is that the effect of [B] on total scrap in the region of slower monomer feed rates is exactly opposite to that in the region of faster monomer feed rates. These two opposite actions counteract each other in computing the standardized effects of the parameter [B] and, thereby, result in reduction in the magnitude of the standardized effect.

\section{Effect of Carboxylic Seed Latex Particles}

It has been speculated that intensive coagulation among interactive particles must occur during monomer addition in the factorial design. This results in a large quantity of coagulum but a quite small $\Delta V$, as shown in Table II. A series of experiments using carboxylic seed particles was carried out for a better understanding of particle growth mechanisms involved in the semibatch surfactant-free emulsion polymerization system. The seed particles contain $2.5 \mathrm{wt} \%$ AA based on total polymer and have an average particle size $\left(d_{\mathrm{s}}\right)$ of $187 \mathrm{~nm}$. The carboxylic seed particles are more stable toward the severe reaction environment because of the presence of $-\mathrm{COOH}\left(\right.$ or $-\mathrm{COO}^{-}$) on particle surfaces. Thus, these seed particles should have a better chance to survive during polymerization. This speculation suggests relatively large $\Delta V$ due to significant limited flocculation.

The experimental conditions and results of this study are summarized in Table V. For experiment CS-1, pH of the seed latex was 3.1 and seed particles were not swollen with any monomer before the start of monomer feed. The $\mathrm{pH}$ of the seed latex was adjusted to 9.5 by $\mathrm{NaOH}$ for experiment CS-2. Such an adjustment is expected to increase ionization of $-\mathrm{COOH}$ on the particle surface and improve the stability of the seed latex. The 
Table V. Experiments using carboxylic seed particles ${ }^{a}$ to study particle growth mechanisms

\begin{tabular}{|c|c|c|c|}
\hline \multirow{2}{*}{ Seed latex condition } & $d_{\mathrm{f}}$ & Total scrap & $\Delta V$ \\
\hline & $\mathrm{nm}$ & $\%$ & $\%$ \\
\hline $\begin{array}{l}\text { CS-1 pH 3.1, no monomer } \\
\text { swelling }\end{array}$ & 149 & 0.52 & -95 \\
\hline $\begin{array}{l}\text { CS-2 pH 9.5, no monomer } \\
\text { swelling }\end{array}$ & 151 & 1.15 & -95 \\
\hline $\begin{array}{c}\mathrm{CS}-3 \mathrm{pH} 9.5, \text { swollen with } \\
5 \% \text { monomer }^{\mathrm{b}}\end{array}$ & 169 & 1.58 & -93 \\
\hline
\end{tabular}

${ }^{\mathrm{a}}$ Seed particles containing $2.5 \% \mathrm{AA}, d_{\mathrm{s}}=187 \mathrm{~nm}$. ${ }^{\mathrm{b}}$ Based on total monomer (BA) feed.

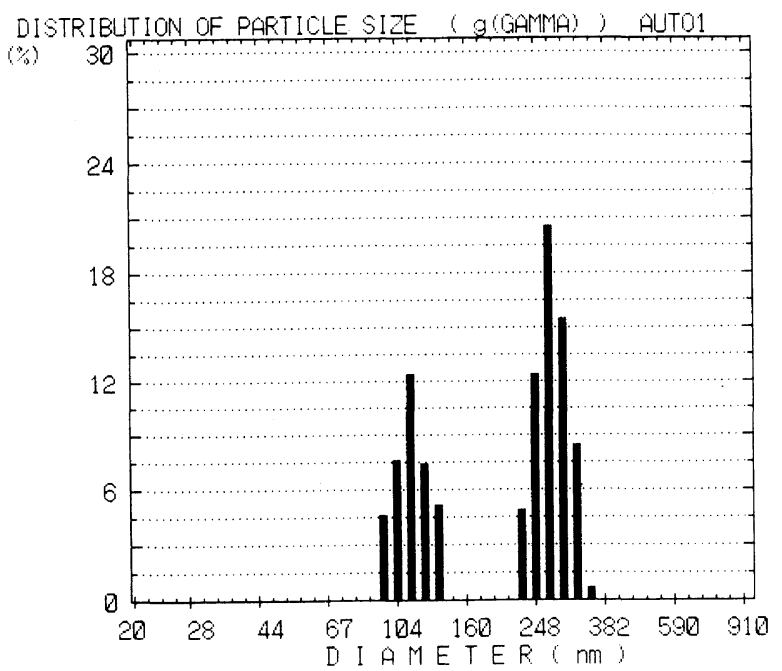

Figure 5. A typical final particle size distribution data for experiment CS-3.

$\mathrm{pH}$ of the seed latex used in experiment CS-3 was the same as that of CS-2, but this time the seed particles were swollen with $5 \%$ monomer (BA) based on total monomer feed before the polymerization of CS-3.

Regardless of the initial state of seed particles, the total scrap obtained from this series of experiments $(<1.58 \%)$ is much less than those obtained from the factorial design (an overall average of $5.62 \%$ ). This supports the postulation that carboxylic seed particles are less prone to the formation of large flocs due to the extra stabilization provided by $-\mathrm{COOH}$ (or $-\mathrm{COO}^{-}$) on particle surfaces (see Table V). $\Delta V$ was $-94 \pm 1 \%$ and $d_{\mathrm{f}}$ is always smaller than $d_{\mathrm{s}}$ in this study. Significant secondary nucleation may thus occur during the reaction since only little coagulum was collected at the end of polymerization. The final particle size data for experiment CS-3 clearly show a bimodal distribution, evidence for the generation of a second crop of primary particles during polymerization (see Figure 5). The final particle size data for the other two experiments (CS-1 and CS-2) also show a bimodal distribution. The particle

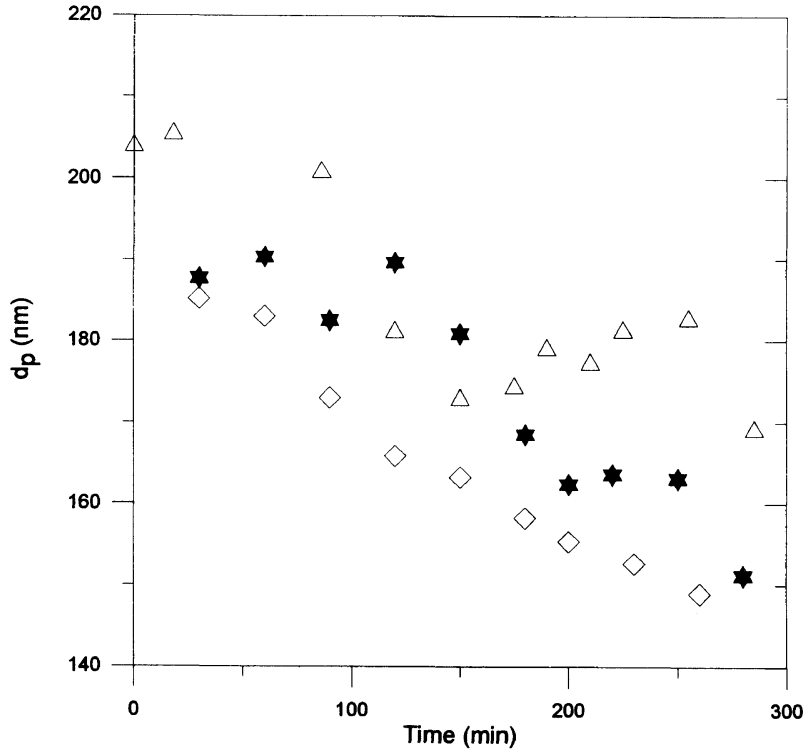

Figure 6. Latex particle size as a function of time. $(\diamond), \mathrm{CS}-1(\mathrm{pH}$ 3.1, seed particles not swollen with monomer); ( ), CS-2 (pH 9.5, seed particles not swollen with monomer); $(\triangle), \mathrm{CS}-3$ (pH 9.5, seed particles swollen with $5 \%$ monomer).

size data $\left(d_{\mathrm{p}}\right)$ for the samples taken during monomer addition are shown in Figure 6. Although the $d_{\mathrm{p}}$-vs.-time data are rather scattered, $d_{\mathrm{p}}$ decreased continuously throughout the reaction for all experiments. This is explained by the fact that newly nucleated primary particles compete effectively with seed particles for the fed monomer. This competitive growth mechanism leads to decrease in $d_{\mathrm{p}}$ as polymerization proceeds. The mechanisms associated with the observed secondary nucleation are not clear at this time and further research is required.

Acknowledgment. The financial support from National Science Council. Taiwan, Republic of China (NSC 86-2216-E-011-010) is gratefully acknowledged.

\section{REFERENCES}

1. B. Li and B. Brooks, Polym. Int., 29, 41 (1992).

2. C. S. Chern, H. Hsu, and F. Y. Lin, J. Appl. Polym. Sci., 60, 1301 (1996).

3. C. S. Chern and F. Y. Lin, J. Appl. Polym. Sci., 61, 989 (1996).

4. C. S. Chern and C. H. Lin, Polym. J., 27, 1094 (1995).

5. C. S. Chern and C. H. Lin, Polym. J., 28, 343 (1996).

6. R. M. Fitch, Br. Polym. J., 5, 467 (1973).

7. R. M. Fitch and C. H. Tsai, in "Polymer Colloids," R. M. Fitch, Ed., Plenum Press, New York, N.Y., 1971, pp. 73-102.

8. B. V. Derjaguin and L. Landau, Acta Physicochim. URSS, 14, 633 (1941).

9. E. J. W. Verwey and J. Th. G. Overbeek, "Theory of the Stability of Lyophobic Colloids," Elsevier, Amsterdam, 1948.

10. X. Z. Kong, C. Pichot, and J. Guillot, Colloid Polym. Sci., 265, 791 (1987). 